Review

\title{
Alloying and Processing Effects on the Aqueous Corrosion Behavior of High-Entropy Alloys
}

\author{
Zhi Tang ${ }^{1}$, Lu Huang ${ }^{1}$, Wei He ${ }^{1,2}$ and Peter K. Liaw ${ }^{1, *}$
}

1 Department of Materials Science and Engineering, The University of Tennessee, Knoxville, TN 37996, USA; E-Mails: tang@utk.edu (Z.T.); lhuang11@utk.edu (L.H.); whe5@utk.edu (W.H.)

2 Department of Mechanical, Aerospace and Biomedical Engineering, The University of Tennessee, Knoxville, TN 37996, USA

* Author to whom correspondence should be addressed; E-Mail: pliaw@utk.edu; Tel.: +1-865-974-6356.

Received: 24 September 2013; in revised form: 9 January 2014 / Accepted: 5 February 2014 / Published: 13 February 2014

\begin{abstract}
The effects of metallurgical factors on the aqueous corrosion behavior of highentropy alloys (HEAs) are reviewed in this article. Alloying (e.g., $\mathrm{Al}$ and $\mathrm{Cu}$ ) and processing (e.g., heat treatments) effects on the aqueous corrosion behavior of HEAs, including passive film formation, galvanic corrosion, and pitting corrosion, are discussed in detail. Corrosion rates of HEAs are calculated using electrochemical measurements and the weight-loss method. Available experimental corrosion data of HEAs in two common solutions [sulfuric acid $\left(0.5 \mathrm{M} \mathrm{H}_{2} \mathrm{SO}_{4}\right)$ and salt water (3.5 weight percent, wt.\%, $\left.\mathrm{NaCl}\right)$ ], such as the corrosion potential $\left(E_{\text {corr }}\right)$, corrosion current density $\left(i_{\text {corr }}\right)$, pitting potential $\left(E_{p i t}\right)$, and passive region $(\Delta E)$, are summarized and compared with conventional corrosionresistant alloys. Possible directions of future work on the corrosion behavior of HEAs are suggested.
\end{abstract}

Key words: high-entropy alloy; aqueous corrosion; sulfuric acid; salt water; alloying; heat treatment

\section{Introduction}

Corrosion of metallic materials is an electrochemical interaction between the metals or alloys and their environment, which is generally detrimental to the proper functions of materials and must be prevented. 
The cost of corrosion in the United States (U.S.) is estimated to have increased from $\$ 276$ billion in 1998 to $\$ 1$ trillion in 2013, which is $6.2 \%$ of the U.S. gross domestic product (GDP) [1,2]. Therefore, the study on the corrosion behavior and degradation mechanism of metals and alloys and the development of corrosion-resistant materials are of enormous economic benefits. Materials to be used in long-term applications as structural or functional materials are expected to possess satisfying corrosion resistance. Noble metals (e.g., Ag, Au, Pt, etc.) are stable and exhibit excellent corrosion resistance even in aggressive environments [3], but the scalability of noble metal applications is restricted by their high cost and poor mechanical properties [3]. Another category of corrosion-resistant materials includes stainless steels, titanium alloys, cobalt-chromium alloys, and so forth, which are widely used in industry. The underlying corrosion-resistant mechanism for these metals or alloys involves the formation of passive films on the surface, which protects the underneath metals or alloys from further corrosion. In addition to the alloy composition, the corrosion behavior of metallic materials is also determined by their microstructures [3]. For example, carbides at grain boundaries of stainless steels deteriorate their corrosion resistance due to the formation of susceptible Cr-depleted zones, which can be diminished by heat treatments [4]. Therefore, metallurgical factors, including alloying and processing (e.g., heat treatments) parameters, are also very important in the development and investigation of corrosion-resistant metals or alloys.

Recently, a novel class of advanced structural materials, called High-Entropy Alloys (HEAs) or Multi-Principal-Element Alloys (MPEAs), has been proposed and developed [5-17]. Compared with conventional alloys containing one or two principal elements, HEAs are usually composed of five or more elements with equimolar or near equimolar elemental fractions, which form disordered solidsolution phases, specifically body-centered-cubic (BCC) and/or face-centered-cubic (FCC) phases. Both single-phase and multi-phase HEAs are expected to exhibit superior corrosion resistance relative to conventional alloys. Most HEAs contain passivating elements, such as $\mathrm{Al}, \mathrm{Cr}$, Mo, etc., which facilitate the formation of passive layers, similar to the case of stainless steels. Meanwhile, HEAs tend to be free of impurities or inclusions, which usually act as corrosion-initiation sites [4]. In particular, some HEAs, forming single-phase solid solutions with homogenous chemical compositions [18,19], are also expected to yield good corrosion resistance, along with their combination of excellent microstructural stability and decent mechanical properties. Such unique properties of HEAs make them good candidates for practical corrosion-resistant applications. A number of investigations on the corrosion behavior of HEAs have been reported, which revealed equivalent or superior corrosion resistance of HEAs in various aqueous environments, as compared with conventional corrosion-resistant alloys, such as 304 stainless steel (SS) [20-35].

This article provides an overview on the aqueous corrosion resistance of HEAs and summarizes the effects of metallurgical variables, particularly alloying and heat-treatment parameters, on their corrosion behaviors.

\section{Review and Discussion}

In terms of alloy design, alloying with different elements and heat treatment are common strategies to enhance/modify material properties. Materials' behavior, including not only mechanical properties (e.g., tensile strength and ductility) but also corrosion resistance, will be influenced by the microstructures produced by alloying different elements and various heat treatments. Elemental alloying can affect the 
corrosion resistance in many different ways, including nobility shifts, dissolution kinetics, passive-film properties, phase structures, the ability to catalyze the cathodic half-reaction, and other corrosioninfluencing parameters [3]. On the other hand, through certain heat treatments, sensitized materials that form Cr-depleted regions along grain boundaries will be stabilized and perform better in aqueous corrosion environments.

\subsection{Corrosion Behavior of Al-Alloying HEAs}

Passivating elements (e.g., Al, Cr, and Ti) tend to encourage the formation and enhance the performance of passive films. A well-known example of passive film enhancement by alloying is the addition of $\mathrm{Cr}$ to steels [3]. A variety of mechanisms were proposed to explain the effect of alloying on the properties of passive films, including: (1) an increase in the thermodynamic stability of the passive film, (2) an enhanced tendency to form a continuous barrier between materials and environments, (3) a decrease in the dissolution kinetics, (4) lower critical currents for passivation, (5) higher rates of repassivation, (6) the suppression of electron transfer, and (7) the superior wear resistance to diminish possibilities for erosion corrosion [26,36-39].

It was previously found that in HEA systems $\mathrm{Al}$ alloying can significantly affect phase-structure evolution $[13,15,26,27,40]$. With increasing $\mathrm{Al}$ contents, lattice types vary from FCC to FCC+BCC, and eventually to $\mathrm{BCC}+\mathrm{B} 2$ (namely a NiAl-type ordered phase structure) structure in several HEA systems, such as $\mathrm{Al}_{x} \mathrm{CoCrCuFeNi}$ [6], $\mathrm{Al}_{x} \mathrm{CoCrFeNi}$ [41], and $\mathrm{Al}_{x} \mathrm{CrCuFeNi}_{2}$ [42]. These changes in crystal structures induced by $\mathrm{Al}$ alloying can significantly affect the corrosion behavior of the HEAs. Considering their effects on the resulting mechanical and corrosion behaviors, Al alloying can be either beneficial or detrimental, which will be discussed in detail below.

Taking the $\mathrm{Al}_{x} \mathrm{CoCrFeNi}(x \leq 1)$ alloy system as an example, although $\mathrm{Al}$ addition enhances the strength of the alloy at the cost of the reduced ductility due to phase changes, from FCC to FCC $+\mathrm{BCC}$, and eventually to $\mathrm{BCC}+\mathrm{B} 2$ lattice structures (Figure 1), excessive $\mathrm{Al}$ addition deteriorates the corrosion resistance of this HEA system in sulfuric acids. Kao and colleagues have reported the corrosion behavior of $\mathrm{Al}_{x} \mathrm{CoCrFeNi}(x \leq 1)$ alloys with different microstructures in $0.5 \mathrm{M} \mathrm{H}_{2} \mathrm{SO}_{4}$ solution. As shown in Figure 1, after immersion tests, few indications of corrosion were observed on the surfaces of both Alfree $(x=0)$ and low $\mathrm{Al}$ content $(x=0.25) \mathrm{Al}_{x} \mathrm{CoCrFeNi}$ alloys, which were composed of single $\mathrm{FCC}$ phase. With an increase in Al to $x=0.5$, the BCC phase emerged, resulting in a mixture of BCC and FCC phases. Signs of corrosion can be observed on $\mathrm{Al}_{0.5} \mathrm{CoCrFeNi}$ surfaces, which were mainly found on the $\mathrm{BCC}$ phase, whereas the FCC phase retained a smooth morphology. The $\mathrm{BCC}+\mathrm{B} 2$ microstructure of a high-Al content $\mathrm{Al}_{x} \mathrm{CoCrFeNi}(x=1)$ alloy was correlated to the lowest corrosion resistance, whereby a rough morphology was observed after immersion tests [26]. The decrease in corrosion resistance of $\mathrm{Al}_{x} \mathrm{CoCrFeNi}(x \leq 1)$ with increasing the $\mathrm{Al}$ concentration was attributed to the formation of pores and the inferior quality of its passive films, which is more distinct at higher temperatures and higher chloride concentrations in chloride-containing solutions [26]. Electrochemical-impedance-spectroscopy (EIS) results have indicated that the passive films become thicker and more dispersive with increasing $\mathrm{Al}$, causing the passivation current $\left(i_{\text {pass }}\right)$ to increase in the $\mathrm{Al}_{x} \mathrm{CoCrFeNi} \mathrm{HEA}$ system when exposed to sulfuric solution [26]. 
Figure 1. Microstructures of $\mathrm{Al}_{x} \mathrm{CoCrFeNi}$ before and after 3-day immersion test in $0.5 \mathrm{M}$ $\mathrm{H}_{2} \mathrm{SO}_{4}$ (Reprinted with permission from [26]).

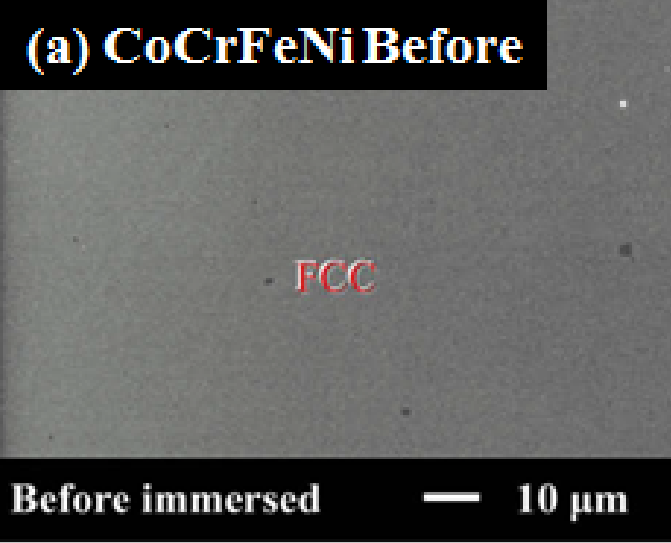

(c) $\mathrm{Al}_{0.25} \mathrm{CoCrFeNi}$ Before
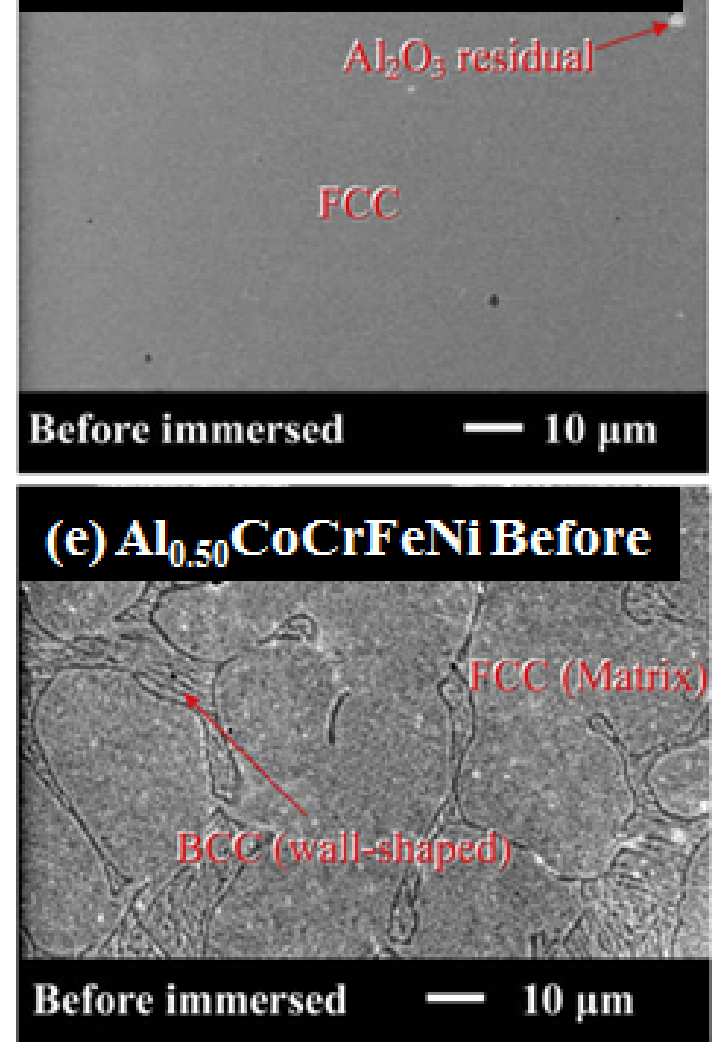

\section{(g) $\mathrm{Al}_{1.00} \mathrm{CoCrFeNiBefore}$}

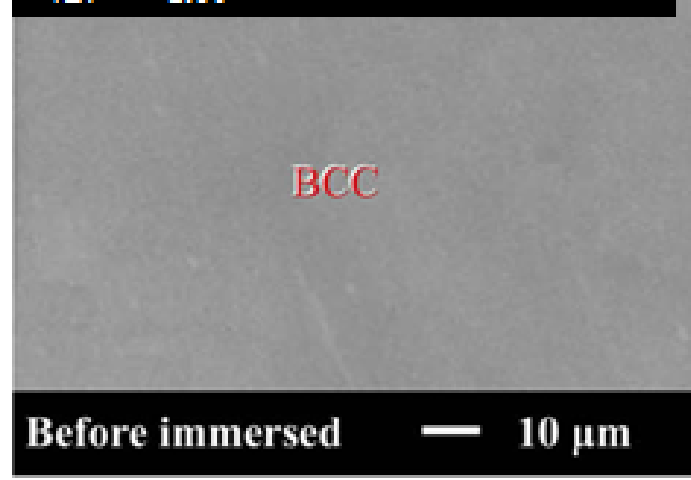

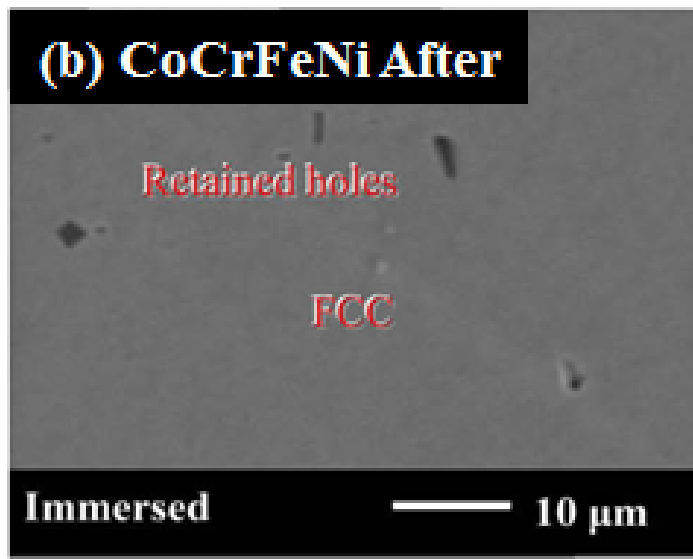

\section{(d) $\mathbf{A l}_{0.25} \mathrm{CoCrFeNi}$ After}

Rreiained liviles
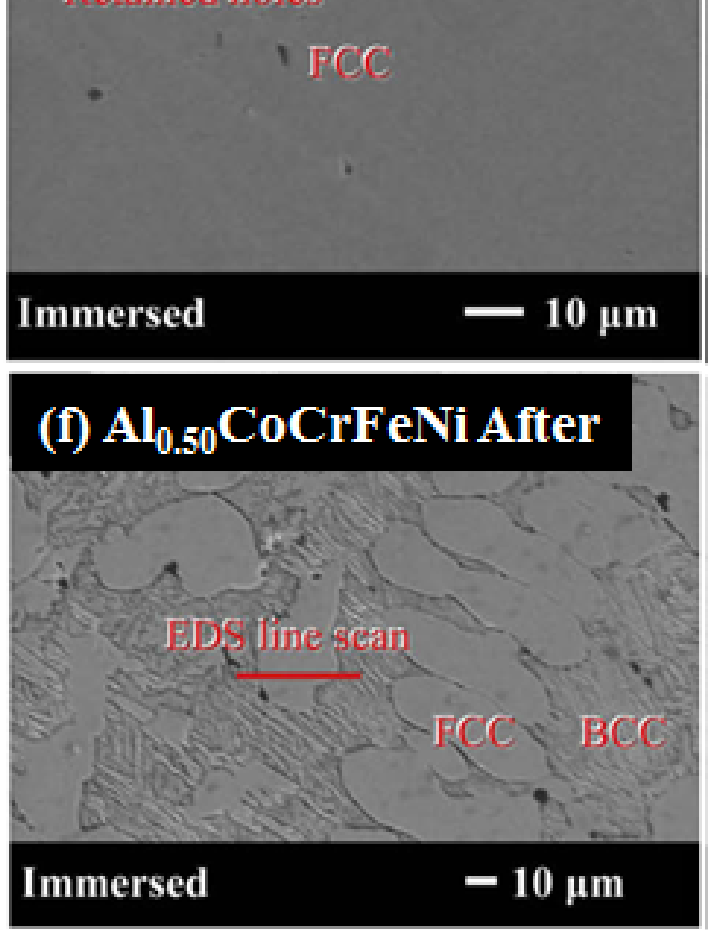

\section{(h) $\mathbf{A l}_{1.00}$ CoCrFeNi After}

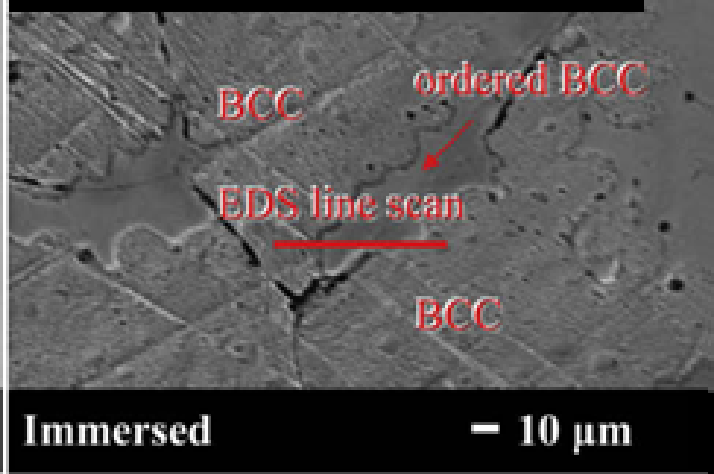


In cases of high $\mathrm{Al}$ ratio $(x \geq 0.5)$, the passive film became unstable and can easily form metastable ion complexes, which eventually dissolve away [26]. Therefore, FCC structures with low Al ratios $(x \leq 0.25)$ have better passive performance and corrosion resistance in the $\mathrm{Al}_{x} \mathrm{CoCrFeNi} H E A$ system. In fact, the concept that alloys with an FCC structure exhibit higher passivity has been previously employed in the design of $18-8$ stainless steels (Fe-18Cr-8Ni in weight percent), the corrosion resistance of which was enhanced by the addition of the austenite (an FCC structure) stabilizer Ni [43].

Similarly, the increase in the corrosion resistance with the decrease in the Al fraction was also found in $\mathrm{Al}_{x} \mathrm{CrFe}_{1.5} \mathrm{MnNi}_{0.5}$ HEAs tested in $\mathrm{H}_{2} \mathrm{SO}_{4}$ and $\mathrm{NaCl}$ solutions [27]. As shown in Figure 2, scanningelectron-microscopy (SEM) micrographs revealed that the general dissolution and pitting-corrosion susceptibility of the HEAs increased as the amount of Al increased [27].

Figure 2. SEM micrographs for the $\mathrm{Al}_{x} \mathrm{CrFe}_{1.5} \mathrm{MnNi}_{0.5}$ alloys with different $\mathrm{Al}$ contents (a) $x=0$, (b) $x=0.3 \mathrm{~mol}$, (c) $x=0.5 \mathrm{~mol}$, and (d) a close-up look at the circled area in micrograph (c), after anodic polarization exceeded the breakdown potential $\left(>1.25 \mathrm{~V}_{\mathrm{SHE}}\right)$ in $0.5 \mathrm{M} \mathrm{H}_{2} \mathrm{SO}_{4}$ (Reprinted with permission from [27]).
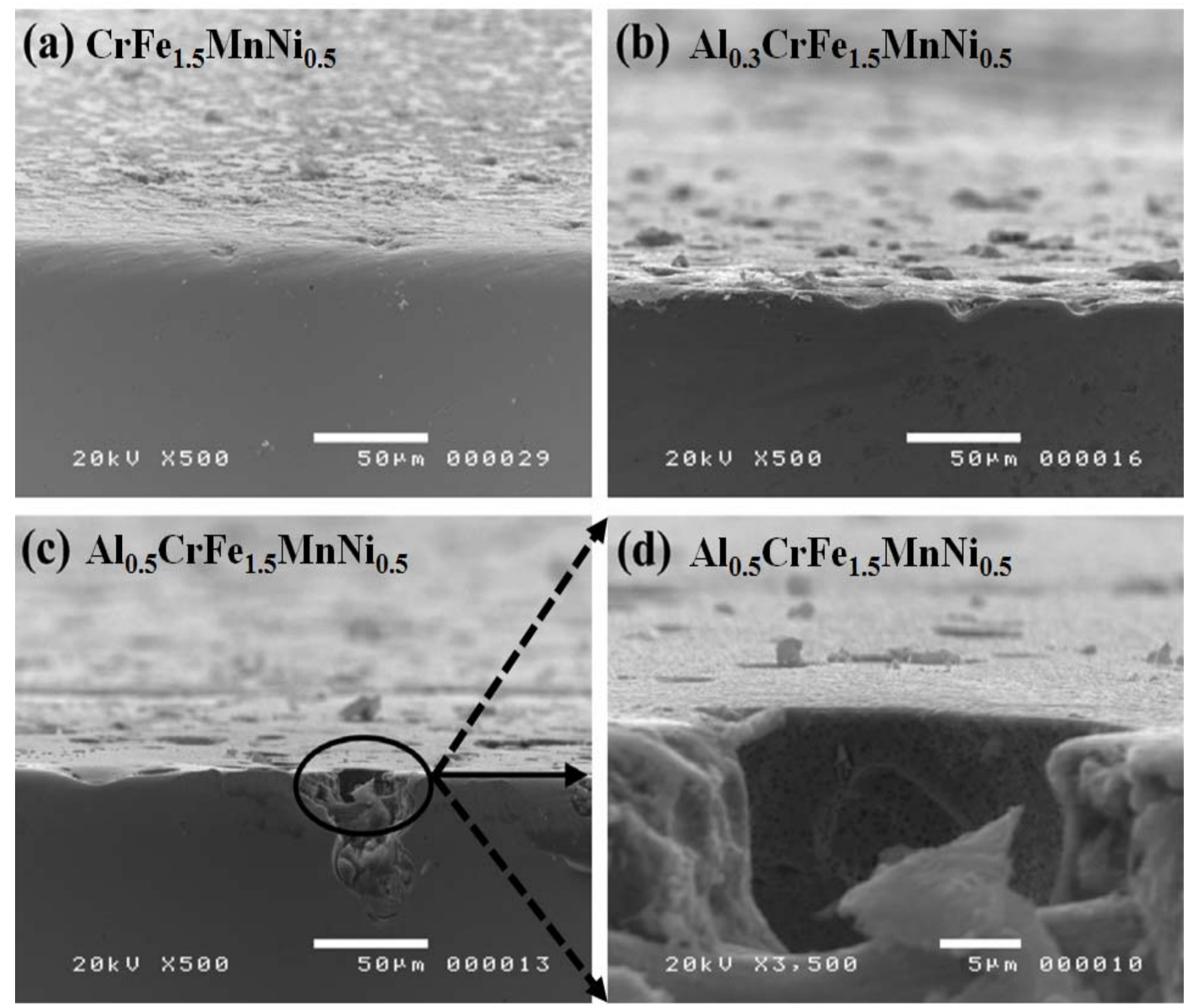
On the surface of the $\mathrm{CrFe}_{1.5} \mathrm{MnNi}_{0.5}$ alloy, there was almost no pitting behavior, while the $\mathrm{Al}_{0.5} \mathrm{CrFe}_{1.5} \mathrm{MnNi}_{0.5}$ alloy suffered from localized corrosion, which was more significant than that of the $\mathrm{Al}_{0.3} \mathrm{CrFe}_{1.5} \mathrm{MnNi}_{0.5}$ alloy. This trend may be due to the fact that $\mathrm{Al}$ tends to form a porous oxide film on the surface of the substrate in the sulfuric acid, resulting in weaker and more porous oxide regions, which suffer from galvanic corrosion [27,44]. On the other hand, different microstructures, changing from $\mathrm{FCC}+\alpha-\mathrm{FeCr} \quad\left(\mathrm{CrFe}_{1.5} \mathrm{MnNi}_{0.5}\right)$, to $\mathrm{FCC}+\mathrm{BCC} \quad\left(\mathrm{Al}_{0.3} \mathrm{CrFe}_{1.5} \mathrm{MnNi}_{0.5}\right)$, and eventually to $\mathrm{BCC}$ $\left(\mathrm{Al}_{0.5} \mathrm{CrFe}_{1.5} \mathrm{MnNi}_{0.5}\right)$ lattice structures may also influence the corrosion behavior. The increase in the $\mathrm{Al}$ content encourages the growth of the BCC phase, whereas the passive films on the surfaces of an FCC structure with low $\mathrm{Al}$ ratios (e.g., $x \leq 0.25$ ) in the $\mathrm{Al}_{x} \mathrm{CrFe}_{1.5} \mathrm{MnNi}_{0.5}$ HEA system tend to be more stable and thus more corrosion-resistant in certain aqueous corrosion environments (e.g., $0.5 \mathrm{M} \mathrm{H}_{2} \mathrm{SO}_{4}$ solution in Table 1). Overall, the passive films formed on the surfaces of an FCC-structured HEA with low Al concentrations $(x \leq 0.25)$ tend to be more stable and corrosion-resistant.

Table 1. Corrosion potential, $E_{\text {corr }}$, corrosion current density $\left(\mu \mathrm{A} / \mathrm{cm}^{2}\right), i_{c o r r}$, pitting potential, $E_{p i t}$, passive region, $\Delta E$, and average corrosion rates (mm/year) of HEAs and conventional alloys in the $0.5 \mathrm{M} \mathrm{H}_{2} \mathrm{SO}_{4}$ solution at room temperature.

\begin{tabular}{cccccc}
\hline Composition & $\begin{array}{c}\boldsymbol{E}_{\text {corr }} \\
\left(\mathbf{m V} \mathbf{V}_{\text {SHE }}\right)\end{array}$ & $\begin{array}{c}\boldsymbol{i}_{\text {corr }} \\
\left(\boldsymbol{\mu} \mathbf{A} / \mathbf{c m}^{2}\right)\end{array}$ & $\boldsymbol{\Delta} \boldsymbol{E}\left(\mathbf{m V}_{\text {SHE}}\right)$ & $\begin{array}{c}\text { Corrosion Rates * } \\
(\mathbf{m m} / \mathbf{y e a r})\end{array}$ & Reference \\
\hline $\mathrm{CoCrFeNi}$ & -81 & 15.8 & 1,098 & 0.12 & {$[26]$} \\
$\mathrm{Al}_{0.25} \mathrm{CoCrFeNi}$ & -95 & 16.7 & 1,092 & 0.13 & {$[26]$} \\
$\mathrm{Al}_{0.5} \mathrm{CoCrFeNi}$ & -84 & 13.4 & 1,083 & 0.11 & {$[26]$} \\
$\mathrm{Al}_{1.0} \mathrm{CoCrFeNi}$ & -94 & 13.1 & 1,090 & 0.11 & {$[26]$} \\
$\mathrm{CrFe}_{1.5} \mathrm{MnNi}_{0.5}$ & -229 & 686 & 1,227 & 6.9 & {$[27]$} \\
$\mathrm{Al}_{0.3} \mathrm{CrFe}_{1.5} \mathrm{MnNi}_{0.5}$ & -194 & 2,390 & 1,176 & 24 & {$[27]$} \\
$\mathrm{Al}_{0.5} \mathrm{CrFe}_{1.5} \mathrm{MnNi}_{0.5}$ & -206 & 5,080 & 1,114 & 52 & {$[27]$} \\
$\mathrm{Stainless} \mathrm{steels}$ & -186 & 74.5 & 1,178 & $0.47-9.3$ & {$[45]$} \\
Copper alloys & - & - & - & $0.06-0.30$ & {$[45,46]$} \\
Nickel alloys & - & - & - & $0.03-0.10$ & {$[45]$} \\
\hline
\end{tabular}

* Average corrosion rates are obtained, including electrochemical measurements and the weight-loss method.

\subsection{Corrosion Behavior of Cu-Alloying HEAs}

Theoretically, the microstructures of HEAs are characterized by solid-solution phases (BCC and/or FCC) due to their high entropy, inhibiting the formation of intermetallic compounds and increasing the solubility of other elements [6]. In HEAs with an equimolar fraction for each element, the configuration entropy increases logarithmically with the number of components, based on the following equation:

$$
\Delta S_{\text {mix }}=R \times \ln (N)
$$

here $N$ is the total number of elements in the solution phase, and $R$ is the ideal gas constant. High-entropy solid-solution phases form due to the contribution from the higher entropy, compared with conventional alloys, according to the definition of the Gibbs free energy of mixing $\left(\Delta G_{m}\right)$ for a solid-solution phase:

$$
\Delta G_{m}=\Delta H_{m}-T \Delta S_{m}
$$


where $\Delta H_{m}$ is the enthalpy of mixing, $\Delta S_{m}$ is the entropy of mixing, and $T$ is the absolute temperature. However, in practice only a few compositions form single high-entropy disordered solid solutions, while others either contain more than one phase, or have elemental partitioning among phases. The main reason may be that the configurational entropy with equimolar and near equimolar fractions of constituent elements may be not high enough to compete with the formation of compound phases. Also, the effect of other entropy sources, such as vibrational entropy, cannot be ignored [17].

For some HEAs with single solid-solution phases, galvanic corrosion is suppressed, since no nobler or less noble phases are present. However, as discussed above, the galvanic corrosion between phases was found in some HEAs with more than one phase. In galvanic corrosion, the corrosion of the least noble phase is accelerated by another nobler phase where the corresponding cathodic half reaction happens [36]. A common example of severe galvanic corrosion is graphitic corrosion in gray cast irons, consisting of graphite flakes (nobler phase) in a matrix of ferrites or pearlites (least noble phase) [36]. Similarly, a good example of galvanic corrosion in HEA systems is $\mathrm{Cu}$ segregation. $\mathrm{Cu}$ tends to segregate as clusters, forming $\mathrm{Cu}$-poor dendrites and $\mathrm{Cu}$-rich interdendrites during solidification due to their weaker bonding energies (chemical mixing enthalpy, $\Delta H^{\text {chem }}$ ) with $\mathrm{Fe}, \mathrm{Co}, \mathrm{Ni}$, and $\mathrm{Cr}[9,13,47,48]$. For example, a well-studied $\mathrm{HEA}, \mathrm{Al}_{0.5} \mathrm{CoCrCuFeNi}$, consists of $\mathrm{Cu}$-rich interdendrites in a $\mathrm{Cu}$-depleted matrix [9,47-49]. When $\mathrm{Al}_{0.5} \mathrm{CoCrCuFeNi}$ corrodes in an aqueous environment, the matrix becomes relatively noble, while $\mathrm{Cu}$-rich interdendrites corrode readily, with the electrically-connected network of $\mathrm{Cu}$-rich interdendrites acting as the cathodic-charge distribution system. The more active $\mathrm{Cu}$-rich interdendrites can be continually consumed by the anodic half-reaction, which is supported by the cathodic half-reaction occurring in the $\mathrm{Cu}$-depleted matrix. Galvanic corrosion between constituent phases also occurs in other $\mathrm{Cu}$-containing HEA systems. Hsu et al. [25] found that $\mathrm{CoCrCu}_{x} \mathrm{FeNi}$ alloys suffered from localized corrosion after immersion tests in aerated 3.5 weight percent (wt.\%) $\mathrm{NaCl}$ solution at room temperature for 30 days. The localized corrosion was found along the $\mathrm{Cu}$-rich interdendrites in both $\mathrm{CoCrCu}_{0.5} \mathrm{FeNi} \quad$ and $\mathrm{CoCrCu}_{1.0} \mathrm{FeNi}$, but not in the $\mathrm{Cu}$-free $\mathrm{CoCrFeNi} \mathrm{HEA}$. Generally, the corrosion of Cu-containing HEAs is mainly attributed to the galvanic corrosion caused by the $\mathrm{Cu}$ segregation. The corrosion resistance generally decreases with the increase of the $\mathrm{Cu}$ concentration.

\subsection{Heat-Treatment Effects on Corrosion Behavior of HEAs}

Heat treatments are commonly adopted in processing conventional alloys. Different heat-treatment processes act differently on the microstructures and properties of the materials. For example, heat treatment of conventional alloys aimed at producing peak hardness and enhanced mechanical performance could result in the growth of precipitates, which can be attacked by galvanic corrosion and pitting [36]. The localized corrosion will be more severe, if the precipitates electrically connect to each other forming a network. On the other hand, certain heat treatments can homogenize the chemical distribution of elements, which is beneficial for the corrosion resistance of the material. A good example is that $\mathrm{Cr}$-carbide precipitates in stainless steels can be re-dissolved, leaving the $\mathrm{Cr}$ evenly dispersed in the parent alloy, via the heat treatment above $1,035{ }^{\circ} \mathrm{C}$, followed by rapid quenching [36].

Based on Equation (2), increasing $\Delta S_{\text {mix }}$ will reduce the Gibbs free energy of HEAs, which stabilizes the solid-solution phase and suppresses the growth of intermetallic precipitates. This effect should be more 
pronounced at elevated temperatures. As discussed above, a more uniform structure is related to a higher corrosion resistance. Thus, such high-entropy effects at greater temperatures homogenize the microstructures and tend to improve the corrosion resistance of HEAs. If the heat-treatment conditions were properly selected, homogenization at certain high temperatures would dissolve $\mathrm{Cr}$-rich and/or $\mathrm{Cu}$ rich phases. The corrosion resistance of these alloys should be enhanced. For example, in the $\mathrm{CoCrCu}_{0.5} \mathrm{FeNi} \mathrm{HEA}$, the $\mathrm{Cu}$-rich phase was successfully dissolved into an $\mathrm{FCC}$ matrix aging at $1,100{ }^{\circ} \mathrm{C}-1,350{ }^{\circ} \mathrm{C}$, which resulted in better corrosion properties, compared with those aged at $350{ }^{\circ} \mathrm{C}-950{ }^{\circ} \mathrm{C}[33]$. It is noteworthy that not all heat treatments are suitable to advance the corrosion resistance of HEAs, as the effect can sometimes be contrary to what was desired. Examples are that several heat-treated HEAs, such as $\mathrm{Al}_{0.5} \mathrm{CoCrFeNi}$ [31] and $\mathrm{CoCrCu}_{0.5} \mathrm{FeNi}$ [33], were reported to be susceptible to corrosion in a $3.5 \mathrm{wt} . \% \mathrm{NaCl}$ solution. In these cases, the heat treatments did not homogenize the microstructure, but instead, promoted the formation and growth of Cr-rich and/or $\mathrm{Cu}$-rich phases rather than forming single-phase microstructures.

\subsection{Comparisons with Conventional Corrosion-Resistant Materials}

Among conventional corrosion-resistant materials, there are two major groups: one group that withstand high-temperature and dry or gaseous corrosion (called heat-resistant alloys, HRAs), and the other that withstand low-temperature aqueous corrosion (called corrosion-resistant alloys, CRAs). Most of the materials are competent for only one application as either HRA or CRA; whereas only a few alloys can be used for both applications (e.g., Inconel 625) [50]. As a new advanced engineering material, the chemical composition and microstructure of some HEAs present many similarities with conventional HRAs and/or CRAs, including the high concentrations of $\mathrm{Cr}, \mathrm{Fe}$, and Ni elements, and a single FCC lattice structure. Meanwhile, as MPEAs, HEAs can be alloyed more heavily than stainless steels and Nibased alloys, meaning that larger amounts of specific elements may possibly be dissolved intentionally to tailor the HEAs for particular environments. Certain HEAs (e.g., $\mathrm{Al}_{x} \mathrm{CoCrFeNi}$ when $x \leq 0.3$ ) have hold better chances to serve as HRAs and/or CRAs, owing to their high-temperature strengths, being homogeneous as a single FCC structure at all temperatures, and lower cost, which leads to a wide range of industrial applications [17,41,51-54]. In fact, the corrosion performance of HEAs is comparable or even superior to that of conventional alloys in certain aqueous corrosion environments, as will be discussed below.

The corrosion resistance of metals or alloys can include several parameters, such as the corrosion potential $\left(E_{c o r r}\right)$, pitting potential $\left(E_{\text {pit }}\right)$, corrosion current density $\left(i_{c o r r}\right)$, and corrosion rate. The $E_{c o r r}$ is the reactivity of the alloy, a higher value of which indicates a more stable material. The $E_{p i t}$ represents the resistance of the material to pitting corrosion. The $i_{c o r r}$ is relevant to the corrosion rate, as will be discussed below. According to the American Society for Testing and Materials (ASTM), G31-12a [55], Standard Guide for Laboratory Immersion Corrosion Testing of Metals, the average corrosion rates can be determined by the weight-loss method, which can be calculated from the following equation:

$$
\text { Corrosion rate }(\mathrm{mm} / \text { year })=\frac{8.76 \times 10^{4} \times W}{A \times T \times D}
$$

here $W$ is the total weight loss in gram after exposure, $A$ is the exposure area of the specimen in $\mathrm{cm}^{2}, T$ is 
the exposure time in hour, and $D$ is the density of the alloy in $\mathrm{g} / \mathrm{cm}^{3}$. This method is applicable to uniform corrosion. If the surface examination shows that the major types of corrosion are localized corrosion and/or pitting, the corrosion rate is usually determined using electrochemical-polarization measurements. Based on ASTM G102-89 [56], Standard Practice for Calculation of Corrosion Rates and Related Information from Electrochemical Measurements, Faraday's Law can be used to calculate the corrosion rate in terms of the mass-loss rate:

$$
\text { Corrosion rate }(\mathrm{mm} / \text { year })=3.27 \times 10^{-3} \times \frac{i_{\text {corr }}}{\rho} \times E W
$$

here $i_{\text {corr }}$ is the corrosion current density in $\mu \mathrm{A} / \mathrm{cm}^{2}, \rho$ is the density in $\mathrm{g} / \mathrm{cm}^{3}$, and $E W$ is the alloy equivalent weight, which is given by:

$$
E W=\left(\sum \frac{n_{i} f_{i}}{W_{i}}\right)^{-1}
$$

here $n_{i}$ is the valence of the $i$ th element of the alloy, $f_{i}$ is the mass fraction of the $i$ th element in the alloy, and $W_{i}$ is the atomic weight of the $i$ th element in the alloy. The density of HEAs is calculated, using the rule of mixtures of pure elements, as shown below:

$$
\rho_{\text {mix }}=\frac{\sum c_{i} A_{i}}{\sum c_{i} A_{i} / \rho_{i}}
$$

here $c_{i}, A_{i}$, and $\rho_{i}$ are the atomic fraction, the atomic weight, and the density of the element, $i$, respectively. The $\rho_{i}$ values of the alloying elements are taken from [57].

A detailed comparison on the corrosion behavior between conventional corrosion-resistant alloys and HEAs is demonstrated in Table 2. Corrosion parameters, including $E_{c o r r}, E_{p i t}$, and $i_{c o r r}$ of HEAs and stainless steels in $3.5 \mathrm{wt} . \% \mathrm{NaCl}$ solution at room temperature are summarized in detail (Table 2 and Figure 3). Generally, the corrosion potential and pitting potential of HEAs are comparable with those of 304 stainless steels. However, the corrosion current density of some HEAs tends to be much lower, which suggests a lower corrosion rate, as indicated in Equation (4). A comparison of the corrosion rate (mm/year) calculated from electrochemical measurements and the weight loss method is also shown in Table 2 and plotted in Figure 3. Data obtained from other materials, such as stainless steels, low alloy steels, low carbon steels, nickel alloys, aluminum alloys, and titanium alloys, and bulk metallic glasses (BMGs) are included for comparison. Corrosion rates of HEAs in the $3.5 \mathrm{wt} \% \mathrm{NaCl}$ solution at room temperature are generally lower than those of low carbon steels and low alloy steels, and comparable with stainless steels and aluminum alloys. It is notable that the $\mathrm{CoCrCu}_{0.5} \mathrm{FeNi}$ HEA heat-treated at 1,250 ${ }^{\circ} \mathrm{C}$ for $24 \mathrm{~h}$ exhibits comparably low corrosion rate with nickel alloys and titanium alloys. The outstanding corrosion resistance of the heat-treated $\mathrm{CoCrCu}_{0.5} \mathrm{FeNi}$ HEA can be explained by the fact that the heat treatment at $1,250{ }^{\circ} \mathrm{C}$ for $24 \mathrm{~h}$ is sufficient to dissolve $\mathrm{Cu}$-rich segregation adjacent to grain boundaries in $\mathrm{CoCrCu}_{0.5} \mathrm{FeNi} \mathrm{HEA}$, as discussed previously. Similarly, corrosion properties of HEAs in the $0.5 \mathrm{M} \mathrm{H}_{2} \mathrm{SO}_{4}$ solution are listed in Table 1. Several HEAs, such as CoCrFeNi, have good corrosion properties, including relative high corrosion potentials, low corrosion current densities, large passive regions, and low corrosion rates, compared with conventional alloys (Figure 4). The enhanced corrosion 
properties of $\mathrm{CoCrFeNi}$ are attributed to its single FCC solid-solution microstructure, which is favorable for the formation of a stable passive film. Thus, it is believed that some certain compositions with a proper processing method should make HEAs as good corrosion-resistant alloy candidates.

Table 2. Corrosion potential, $E_{\text {corr }}$, corrosion current density $\left(\mu \mathrm{A} / \mathrm{cm}^{2}\right), i_{c o r r}$, pitting potential, $E_{p i t}$, and average corrosion rates (mm/year) of HEAs and other materials in the salt water (3.5 wt.\% $\mathrm{NaCl})$ solution at room temperature.

\begin{tabular}{|c|c|c|c|c|c|c|}
\hline Composition & $\begin{array}{c}\text { Heat } \\
\text { Treatment } \\
\text { Condition }\end{array}$ & $\begin{array}{c}E_{\text {corr }} \\
\left(\mathbf{V}_{\mathrm{SHE}}\right)\end{array}$ & $\begin{array}{c}i_{\text {corr }} \\
\left(\mu \mathrm{A} / \mathrm{cm}^{2}\right)\end{array}$ & $\begin{array}{c}E_{p i t} \\
\left(V_{\text {SHE }}\right)\end{array}$ & $\begin{array}{l}\text { Corrosion Rates* } \\
\quad(\mathrm{mm} / \text { year })\end{array}$ & Reference \\
\hline $\mathrm{CoCrFeNi}$ & As-cast & -0.01 & 0.03 & 0.55 & $3.3 \times 10^{-4}$ & {$[25]$} \\
\hline $\mathrm{CoCrCu}_{0.5} \mathrm{FeNi}$ & As-cast & -0.04 & 0.72 & 0.34 & $7.5 \times 10^{-4}$ & {$[25]$} \\
\hline $\mathrm{CoCrCu}_{0.5} \mathrm{FeNi}$ & $350^{\circ} \mathrm{C} / 24 \mathrm{~h}$ & -0.26 & 0.04 & 0.31 & $3.1 \times 10^{-4}$ & {$[33]$} \\
\hline $\mathrm{CoCrCu}_{0.5} \mathrm{FeNi}$ & $500{ }^{\circ} \mathrm{C} / 24 \mathrm{~h}$ & -0.17 & 0.12 & 0.31 & $9.2 \times 10^{-4}$ & {$[33]$} \\
\hline $\mathrm{CoCrCu}_{0.5} \mathrm{FeNi}$ & $650{ }^{\circ} \mathrm{C} / 24 \mathrm{~h}$ & -0.24 & 0.02 & 0.27 & $1.7 \times 10^{-4}$ & {$[33]$} \\
\hline $\mathrm{CoCrCu}_{0.5} \mathrm{FeNi}$ & $800^{\circ} \mathrm{C} / 24 \mathrm{~h}$ & -0.04 & 0.02 & 0.26 & $1.3 \times 10^{-4}$ & {$[33]$} \\
\hline $\mathrm{CoCrCu}_{0.5} \mathrm{FeNi}$ & $950{ }^{\circ} \mathrm{C} / 24 \mathrm{~h}$ & -0.18 & 0.11 & 0.28 & $8.6 \times 10^{-4}$ & {$[33]$} \\
\hline $\mathrm{CoCrCu}_{0.5} \mathrm{FeNi}$ & $1,100^{\circ} \mathrm{C} / 24 \mathrm{~h}$ & -0.15 & 0.14 & 0.30 & $1.1 \times 10^{-3}$ & {$[33]$} \\
\hline $\mathrm{CoCrCu}_{0.5} \mathrm{FeNi}$ & $1,250^{\circ} \mathrm{C} / 24 \mathrm{~h}$ & -0.02 & 0.01 & 0.29 & $4.0 \times 10^{-5}$ & {$[33]$} \\
\hline $\mathrm{CoCrCu}_{0.5} \mathrm{FeNi}$ & $1,350^{\circ} \mathrm{C} / 24 \mathrm{~h}$ & -0.16 & 0.05 & 0.30 & $3.6 \times 10^{-4}$ & {$[33]$} \\
\hline $\mathrm{Al}_{0.5} \mathrm{CoCrFeNi}$ & As-cast & -0.32 & 0.17 & 0.38 & $1.3 \times 10^{-3}$ & {$[31]$} \\
\hline $\mathrm{Al}_{0.5} \mathrm{CoCrFeNi}$ & $350{ }^{\circ} \mathrm{C} / 24 \mathrm{~h}$ & -0.31 & 6.40 & 0.43 & $5.1 \times 10^{-2}$ & [31] \\
\hline $\mathrm{Al}_{0.5} \mathrm{CoCrFeNi}$ & $500{ }^{\circ} \mathrm{C} / 24 \mathrm{~h}$ & -0.05 & 1.58 & 0.53 & $1.3 \times 10^{-2}$ & {$[31]$} \\
\hline $\mathrm{Al}_{0.5} \mathrm{CoCrFeNi}$ & $650{ }^{\circ} \mathrm{C} / 24 \mathrm{~h}$ & 0.29 & 0.53 & 0.96 & $4.2 \times 10^{-3}$ & {$[31]$} \\
\hline $\mathrm{Al}_{0.5} \mathrm{CoCrFeNi}$ & $800{ }^{\circ} \mathrm{C} / 24 \mathrm{~h}$ & -0.39 & 0.30 & 0.39 & $2.4 \times 10^{-3}$ & {$[31]$} \\
\hline $\mathrm{Al}_{0.5} \mathrm{CoCrFeNi}$ & $950{ }^{\circ} \mathrm{C} / 24 \mathrm{~h}$ & -0.29 & 2.22 & 0.43 & $1.8 \times 10^{-2}$ & {$[31]$} \\
\hline Stainless steels & - & $0.02 * *$ & $0.06^{* *}$ & $0.72 * *$ & $5.3 \times 10^{-4}-3.4 \times 10^{-3}$ & {$[25,31]$} \\
\hline Low alloy steels & - & - & - & - & $6.9 \times 10^{-2}-1.5 \times 10^{-1}$ & {$[45]$} \\
\hline Low carbon steels & - & - & - & - & $9.7 \times 10^{-2}-8.1 \times 10^{-1}$ & {$[45,58]$} \\
\hline Nickel alloys & - & - & - & - & $3.1 \times 10^{-5}-1.4 \times 10^{-4}$ & {$[45,58]$} \\
\hline Aluminum alloys & - & - & - & - & $8.9 \times 10^{-4}-2.9 \times 10^{-3}$ & {$[45,59]$} \\
\hline Titanium alloys & - & - & - & - & $8.0 \times 10^{-6}-2.5 \times 10^{-4}$ & {$[45]$} \\
\hline $\begin{array}{l}\text { Bulk metallic } \\
\text { glasses }\end{array}$ & - & - & - & - & $1.0 \times 10^{-3}-2.9 \times 10^{-1}$ & {$[60]$} \\
\hline
\end{tabular}

* Average corrosion rates are obtained, including electrochemical measurements and the weight-loss method. Some corrosion rates of conventional alloys were tested in seawater for comparison.** Specifically, the corrosion data refer to the $304 \mathrm{~L}$ stainless steel. 
Figure 3. A comparison to average corrosion rates (mm/year) between HEAs and other materials in the $3.5 \mathrm{wt} . \% \mathrm{NaCl}$ solution at room temperature $[25,31,33,45,58,59,60]$.

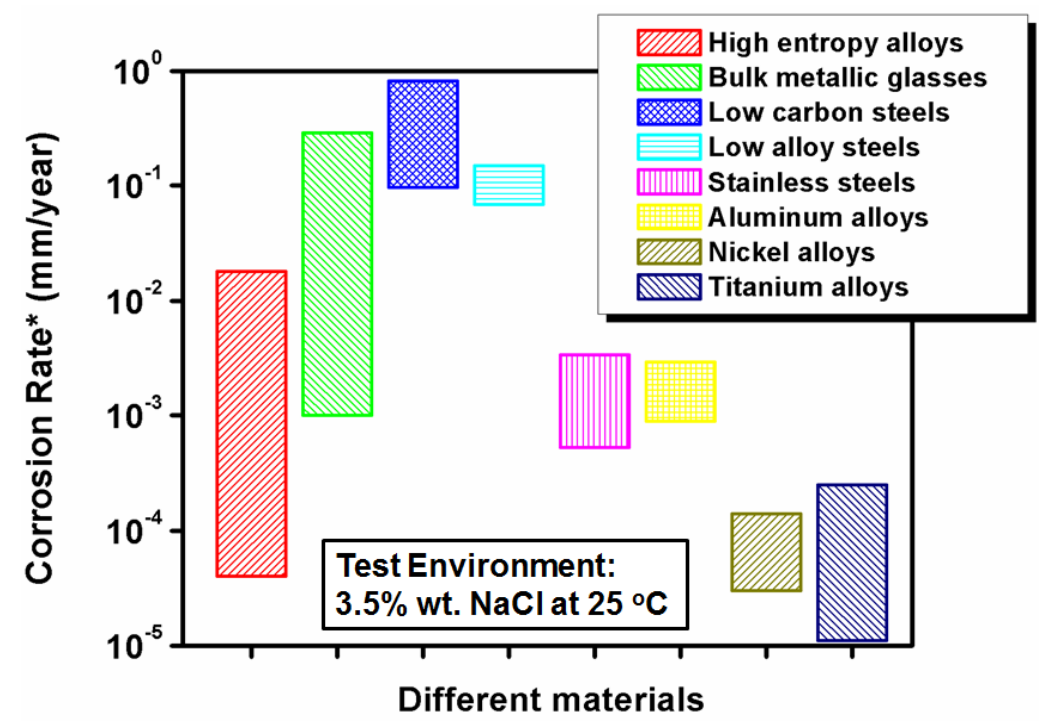

* Average corrosion rates are obtained, including electrochemical measurements and weight loss method. Some corrosion rates of conventional alloys were tested in seawater for comparison.

Figure 4. A comparison to average corrosion rates (mm/year) between HEAs and conventional alloys in the $0.5 \mathrm{M} \mathrm{H}_{2} \mathrm{SO}_{4}$ solution at room temperature $[26,27,45,46]$.

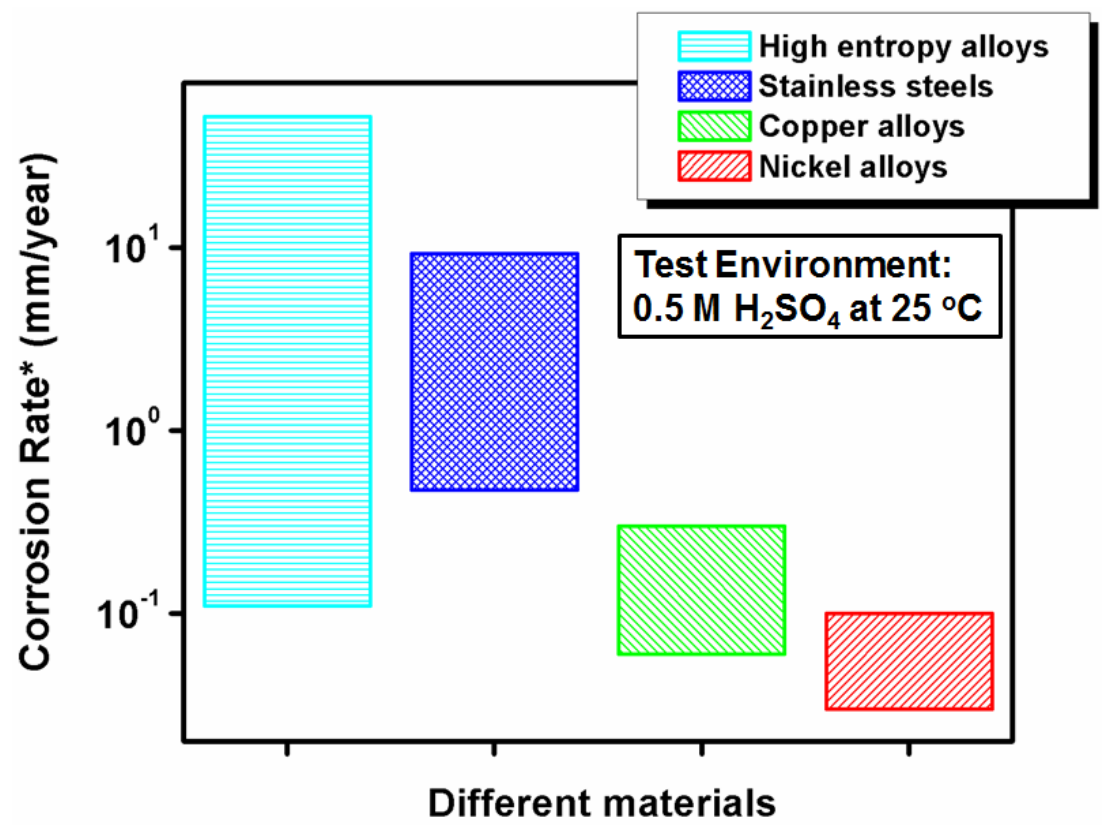

* Average corrosion rates are obtained, including electrochemical measurements and weight loss method.

\section{Suggested Future Work}

Based on a number of publications focusing on the aqueous corrosion of HEAs in various environments, synergistic effects of more than one environmental factor have not been rigorously incorporated in this cutting-edge research area. From the experimental perspective, several following uncertainties and future directions are suggested for researchers' consideration: 
(1) Residual stresses from cold working, hot forging, and other sources can lead to higher corrosion rates, causing stress corrosion cracking (SCC) [61]. However, cold working and hot forging, such as upset forging, tend to effectively remove casting defects, refine microstructures, improve the strengths, and accelerate the homogenization process of as-cast alloys [62]. The effects of residual stresses on the corrosion behavior of HEAs can be further investigated.

(2) Al addition has a positive influence on mechanical properties but a negative influence on corrosion resistance of some HEA systems, such as $\mathrm{Al}_{x} \mathrm{CoCrFeNi}$ systems. The $\mathrm{Al}$ ratio can be tuned to determine an optimal HEA composition, which yields a combination of both high strength and good corrosion properties.

(3) Welding has a number of effects on the metallurgy and corrosion resistance of alloys, because the uncontrolled melting and re-solidification will lead to grain size and chemical composition changes. The corrosion behavior of this region, known as the heat-affected zone (HAZ), can be an interesting topic to be studied.

(4) Corrosion fatigue is an important but complex mode of failure for high-performance structural metals operating in deleterious environments [63]. The corrosion-fatigue behavior of HEAs in aqueous electrolytes can be characterized with an effective life-prediction model.

(5) A single-phase alloy without precipitates and elemental segregation tends to exert better corrosion properties. Exploration on the corrosion behavior of single-phase HEAs in both as-cast and heat-treated conditions will complete the current database on the corrosion properties of HEAs.

\section{Conclusions}

This article reviews the current progress concerning the investigations on the aqueous corrosion behavior of HEAs. The corrosion of two major groups of HEAs, Al- and Cu-containing HEAs, is discussed.

(1) Al-alloying affects the passive film properties of HEAs. In the Al-containing HEA family, an increase in the $\mathrm{Al}$ concentration generally leads to the formation of porous passive films and poor corrosion resistance. Moreover, the increase in the $\mathrm{Al}$ content encourages the growth of the $\mathrm{BCC}$ phase in $\mathrm{AlxCoCrFeNi}$ and $\mathrm{AlxCrFe}{ }_{1.5} \mathrm{MnNi}_{0.5}$ HEA systems, in which the passive films tend to be less stable and more susceptible to corrosion, as compared with that formed on the surfaces of an FCC structured HEAs with low Al ratios (e.g., $\mathrm{x} \leq 0.3$ ).

(2) In $\mathrm{Cu}$-containing $\mathrm{HEA}$ systems, $\mathrm{Cu}$ alloying was found to exert deleterious effects on the corrosion resistance, which induces galvanic corrosion due to its segregation. The corrosion resistance of $\mathrm{Cu}-$ free HEAs is generally better than $\mathrm{Cu}$-containing HEAs.

(3) Heat treatments at appropriate temperatures, which homogenize the microstructure and dissolve segregation phases (e.g., $\mathrm{Cu}$-rich phases in $\mathrm{Cu}$-containing HEAs), can enhance the corrosion resistance of HEAs.

(4) HEAs with a single-phase microstructure, especially an FCC structure, tend to have better corrosion resistance than multi-phase HEAs. Some single FCC-structure HEA, such as $\mathrm{CoCrFeNi}$, are comparably and even more corrosion-resistant than conventional alloys. 
Thus, it is concluded that HEAs with a proper design in alloy compositions and post-casting treatments can be developed for their promising applications as aqueous corrosion-resistant structural materials.

\section{Acknowledgement}

Zhi Tang and Peter K. Liaw acknowledge the financial support from the Department of Energy (DOE), Office of Nuclear Energy's Nuclear Energy University Program (NEUP) 00119262, with R.O. Jensen, Jr., Lizhen Tan, and Sue Lesica as program managers. Peter K. Liaw thanks DOE for the support through project DE-FE-0011194 with the project manager, S. Markovich, and the U.S. Army Research Office project (W911NF-13-1-0438) with the program manager, Suveen N. Mathaudhu. Lu Huang and Wei He are very grateful for the support from the US National Science Foundation (CMMI-1100080).

\section{Conflicts of Interest}

The authors declare no conflict of interest.

\section{References}

1. Koch, G.H.; Brongers, M.P.; Thompson, N.G.; Virmani, Y.P.; Payer, J.H. Corrosion cost and preventive strategies in the United States; U.S. Federal Highway Administration: Washington, DC, USA, 2001; Publication No. FHWA-RD-01-156.

2. G2MT Labs, LLC. Available online: http://www.g2mtlabs.com/cost-of-corrosion/ (accessed on 23 September 2013).

3. Cramer, S.D.; Covino, B.S., Jr., Eds. ASM Handbook Volume 13A: Corrosion: Fundamentals, Testing, and Protection; ASM International: Novelty, OH, USA, 2003.

4. Frankel, G.S. Introduction to metallurgically influenced corrosion. ASM Handbook Volume 13A: Corrosion: Fundamentals, Testing, and Protection; ASM International: Novelty, OH, USA, 2003; p. 257.

5. Cantor, B.; Chang, I.T.H.; Knight, P.; Vincent, A.J.B. Microstructural development in equiatomic multicomponent alloys. Mater. Sci. Eng. A 2004, 375, 213-218.

6. Yeh, J.W.; Chen, S.K.; Lin, S.J.; Gan, J.Y.; Chin, T.S.; Shun, T.T.; Tsau, C.H.; Chang, S.Y. Nanostructured high-entropy alloys with multiple principal elements: novel alloy design concepts and outcomes. Adv. Eng. Mater. 2004, 6, 299-303.

7. Zhang, Y.; Zhou, Y.J.; Lin, J.P.; Chen, G.L.; Liaw, P.K. Solid-solution phase formation rules for multi-component alloys. Adv. Eng. Mater. 2008, 10, 534-538.

8. Senkov, O.N.; Wilks, G.B.; Miracle, D.B.; Chuang, C.P.; Liaw, P.K. Refractory high-entropy alloys. Intermetallics 2010, 18, 1758-1765.

9. Hemphill, M.A.; Yuan, T.; Wang, G.Y.; Yeh, J.W.; Tsai, C.W.; Chuang, A.; Liaw, P.K. Fatigue behavior of $\mathrm{Al}_{0.5} \mathrm{CoCrCuFeNi}$ high entropy alloys. Acta. Mater. 2012, 60, 5723-5734.

10. Zhang, Y.; Yang, X.; Liaw, P.K. Alloy design and properties optimization of high-entropy alloys. JOM 2012, 64, 830-838. 
11. Guo, W.; Dmowski, W.; Noh, J.-Y.; Rack, P.; Liaw, P.; Egami, T. Local atomic structure of a highentropy alloy: an x-ray and neutron scattering study. Metall. Mater. Trans. A 2013, 44, 1994-1997.

12. Zhang, Y.; Zuo, T.; Cheng, Y.; Liaw, P.K. High-entropy Alloys with High Saturation Magnetization, Electrical Resistivity, and Malleability. Sci. Rep. 2013, 3, 1455.

13. Tang, Z.; Gao, M.C.; Diao, H.; Yang, T.; Liu, J.; Zuo, T.; Zhang, Y.; Lu, Z.; Cheng, Y.; Zhang, Y.; et al. Aluminum alloying effects on lattice types, microstructures, and mechanical behavior of high-entropy alloys systems. JOM 2013, 65, 1848-1858.

14. Ma, S.G.; Zhang, S.F.; Gao, M.C.; Liaw, P.K.; Zhang, Y. A Successful Synthesis of the $\mathrm{CoCrFeNiAl}_{0.3}$ Single-Crystal, High-Entropy Alloy by Bridgman Solidification. JOM 2013, 65, 1751-1758.

15. Welk, B.A.; Williams, R.E.A.; Viswanathan, G.B.; Gibson, M.A.; Liaw, P.K.; Fraser, H.L. Nature of the interfaces between the constituent phases in the high entropy alloy CoCrCuFeNiAl. Ultramicroscopy 2013, 134, 193-199.

16. He, J.Y.; Liu, W.H.; Wang, H.; Wu, Y.; Liu, X.J.; Nieh, T.G.; Lu, Z.P. Effects of Al addition on structural evolution and tensile properties of the FeCoNiCrMn high-entropy alloy system. Acta Mater. 2014, 62, 105-113.

17. Zhang, Y.; Zuo, T.T.; Tang, Z.; Gao, M.C.; Dahmen, K.A.; Liaw, P.K.; Lu, Z.P. Microstructures and properties of high-entropy alloys. Prog. Mater Sci. 2014, 61, 1-93.

18. Yao, M.J.; Pradeep, K.G.; Tasan, C.C.; Raabe, D. A novel, single phase, non-equiatomic FeMnNiCoCr high-entropy alloy with exceptional phase stability and tensile ductility. Scripta Mater. 2014, 72, 5-8.

19. Lucas, M.S.; Wilks, G.B.; Mauger, L.; Munoz, J.A.; Senkov, O.N.; Michel, E.; Horwath, J.; Semiatin, S.L.; Stone, M.B.; Abernathy, D.L.; Karapetrova, E. Absence of long-range chemical ordering in equimolar FeCoCrNi. Appl. Phys. Lett. 2012, 100, 251907.

20. Chen, Y.Y.; Duval, T.; Hung, U.D.; Yeh, J.W.; Shih, H.C. Microstructure and electrochemical properties of high entropy alloys - a comparison with type-304 stainless steel. Corros. Sci. 2005, 47, 2257-2279.

21. Chen, Y.Y.; Hong, U.T.; Shih, H.C.; Yeh, J.W.; Duval, T. Electrochemical kinetics of the high entropy alloys in aqueous environments - a comparison with type 304 stainless steel. Corros. Sci. 2005, 47, 2679-2699.

22. Chen, Y.Y.; Hong, U.T.; Yeh, J.W.; Shih, H.C. Selected corrosion behaviors of a $\mathrm{Cu}_{0.5} \mathrm{NiAlCoCrFeSi}$ bulk glassy alloy in $288{ }^{\circ} \mathrm{C}$ high-purity water. Scripta Mater. 2006, 54, 1997-2001.

23. Chou, Y.L.; Yeh, J.W.; Shih, H.C. The effect of molybdenum on the corrosion behaviour of the high-entropy alloys $\mathrm{Co}_{1.5} \mathrm{CrFeNi}_{1.5} \mathrm{Ti}_{0.5} \mathrm{Mox}$ in aqueous environments. Corros. Sci. 2010, 52, 25712581.

24. Doğan, Ö.; Nielsen, B.; Hawk, J. Elevated-temperature corrosion of $\mathrm{CoCrCuFeNiAl}_{0.5} \mathrm{Bx}$ high-entropy alloys in simulated syngas containing H2S. Oxid. Met. 2013, 80, 177-190.

25. Hsu, Y.-J.; Chiang, W.-C.; Wu, J.-K. Corrosion behavior of FeCoNiCrCux high-entropy alloys in 3.5\% sodium chloride solution. Mater. Chem. Phys. 2005, 92, 112-117. 
26. Kao, Y.-F.; Lee, T.-D.; Chen, S.-K.; Chang, Y.-S. Electrochemical passive properties of AlxCoCrFeNi (x = 0, 0.25, 0.50, 1.00) alloys in sulfuric acids. Corros. Sci. 2010, 52, 1026-1034.

27. Lee, C.P.; Chang, C.C.; Chen, Y.Y.; Yeh, J.W.; Shih, H.C. Effect of the aluminium content of Alx $\mathrm{CrFe}_{1.5} \mathrm{MnNi}_{0.5}$ high-entropy alloys on the corrosion behaviour in aqueous environments. Corros. Sci. 2008, 50, 2053-2060.

28. Lee, C.P.; Chen, Y.Y.; Hsu, C.Y.; Yeh, J.W.; Shih, H.C. The Effect of Boron on the Corrosion Resistance of the High Entropy Alloys $\mathrm{Al}_{0.5} \mathrm{CoCrCuFeNiB}_{\mathrm{x}}$. J. Electrochem. Soc. 2007, 154, C424.

29. Lee, C.P.; Chen, Y.Y.; Hsu, C.Y.; Yeh, J.W.; Shih, H.C. Enhancing pitting corrosion resistance of Alx $\mathrm{CrFe}_{1.5} \mathrm{MnNi}_{0.5}$ high-entropy alloys by anodic treatment in sulfuric acid. Thin Solid Films 2008, 517, 1301-1305.

30. Li, Q.H.; Yue, T.M.; Guo, Z.N.; Lin, X. Microstructure and Corrosion Properties of AlCoCrFeNi High Entropy Alloy Coatings Deposited on AISI 1045 Steel by the Electrospark Process. Metall. Mater. Trans. A 2012, 44, 1767-1778.

31. Lin, C.-M.; Tsai, H.-L. Evolution of microstructure, hardness, and corrosion properties of high-entropy $\mathrm{Al}_{0.5} \mathrm{CoCrFeNi}$ alloy. Intermetallics 2011, 19, 288-294.

32. Lin, C.-M.; Tsai, H.-L. Effect of annealing treatment on microstructure and properties of high-entropy FeCoNiCrCu${ }_{0.5}$ alloy. Mater. Chem. Phys. 2011, 128, 50-56.

33. Lin, C.-M.; Tsai, H.-L.; Bor, H.-Y. Effect of aging treatment on microstructure and properties of high-entropy $\mathrm{Cu}_{0.5} \mathrm{CoCrFeNi}$ alloy. Intermetallics 2010, 18, 1244-1250.

34. Qiu, X.-W.; Liu, C.-G. Microstructure and properties of $\mathrm{Al}_{2} \mathrm{CrFeCoCuTiNix} \mathrm{high-entropy} \mathrm{alloys}$ prepared by laser cladding. J. Alloys Compd. 2013, 553, 216-220.

35. Qiu, X.-W.; Zhang, Y.-P.; He, L.; Liu, C.-g. Microstructure and corrosion resistance of AlCrFeCuCo high entropy alloy. J. Alloys Compd. 2013, 549, 195-199.

36. Noel, J.J. Effects of metallurgical variables on aqueous corrosion. ASM Handbook, Vol. 13A: Corrosion: Fundamentals, Protection and Prevention; ASM International.: Materials Park, $\mathrm{OH}$, USA, 2003, pp. 258-265.

37. Chuang, M.-H.; Tsai, M.-H.; Wang, W.-R.; Lin, S.-J.; Yeh, J.-W. Microstructure and wear behavior of $\mathrm{AlxCo}_{1.5} \mathrm{CrFeNi}_{1.5}$ Tiy high-entropy alloys. Acta Mater. 2011, 59, 6308-6317.

38. Hsu, C.Y.; Sheu, T.S.; Yeh, J.W.; Chen, S.K. Effect of iron content on wear behavior of $\mathrm{AlCoCrFexMo} \mathrm{Mo}_{0.5} \mathrm{Ni}$ high-entropy alloys. Wear 2010, 268, 653-659.

39. Wu, J.M.; Lin, S.J.; Yeh, J.W.; Chen, S.K.; Huang, Y.S. Adhesive wear behavior of AlxCoCrCuFeNi high-entropy alloys as a function of aluminum content. Wear 2006, 261, 513-519.

40. Tian, F.; Delczeg, L.; Chen, N.; Varga, L.K.; Shen, J.; Vitos, L. Structural stability of $\mathrm{NiCoFeCrAl}_{\mathrm{x}}$ high-entropy alloy from ab initio theory. Phys Rev B 2013, 88, 085128.

41. Wang, W.-R.; Wang, W.-L.; Wang, S.-C.; Tsai, Y.-C.; Lai, C.-H.; Yeh, J.-W. Effects of Al addition on the microstructure and mechanical property of $\mathrm{Al}_{\mathrm{x}} \mathrm{CoCrFeNi}$ high-entropy alloys. Intermetallics 2012, 26, 44-51.

42. Guo, S.; Ng, C.; Liu, C.T. Anomalous solidification microstructures in Co-free AlxCrCuFeNi ${ }_{2}$ highentropy alloys. J. Alloys Compd. 2013, 557, 77-81.

43. Smith, W.F. Structure and Properties of Engineering Alloys; McGraw-Hill: New York, 1993. 
44. Chiang, W.-C.; Luu, W.-C.; Wu, J.-K. Effect of aluminum content on the passivation behavior of $\mathrm{Fe}-\mathrm{Al}$ alloys in sulfuric acid solution. J. Mater. Sci. 2006, 41, 3041-3044.

45. Cramer, S.D.; Covino, B.S., Jr., Eds. ASM Handbook, Volume 13B: Corrosion: Materials; ASM International: Novelty, OH, USA, 2003.

46. Quartarone, G.; Bellomi, T.; Zingales, A. Inhibition of copper corrosion by isatin in aerated $0.5 \mathrm{M}$ $\mathrm{H}_{2} \mathrm{SO}_{4}$. Corros. Sci. 2003, 45, 715-733.

47. Tong, C.-J.; Chen, Y.-L.; Yeh, J.-W.; Lin, S.-J.; Chen, S.-K.; Shun, T.-T.; Tsau, C.-H.; Chang, S.-Y. Microstructure characterization of $\mathrm{Al}_{\mathrm{x}} \mathrm{CoCrCuFeNi}$ high-entropy alloy system with multiprincipal elements. Metall. Mater. Trans. A 2005, 36, 881-893.

48. Tsai, C.W.; Tsai, M.H.; Yeh, J.W.; Yang, C.C. Effect of temperature on mechanical properties of $\mathrm{Al}_{0.5} \mathrm{CoCrCuFeNi}$ wrought alloy. J. Alloys Compd. 2010, 490, 160-165.

49. Laktionova, M.A.; Tabchnikova, E.D.; Tang, Z.; Liaw, P.K. Mechanical properties of the high-entropy alloy $\mathrm{Ag}_{0.5} \mathrm{CoCrCuFeNi}$ at temperatures of 4.2-300 K. Low Temp. Phys. 2013, 39, 630-632.

50. Rebak, R.B. Effects of Metallurgical Variables on the Corrosion of High-Nicekl Alloys. ASM Handbook Volume 13A: Corrosion: Fundamentals, Testing, and Protection; ASM International: Novelty, OH, USA, 2003; pp. 279-286.

51. Zhang, C.; Zhang, F.; Chen, S.; Cao, W. Computational thermodynamics aided high-entropy alloy design. JOM 2012, 64, 839-845.

52. Chou, H.P.; Chang, Y.S.; Chen, S.K.; Yeh, J.W. Microstructure, thermophysical and electrical properties in $\mathrm{Al}_{\mathrm{x}} \mathrm{CoCrFeNi}(0<=\mathrm{x}<=2)$ high-entropy alloys. Mater. Sci. Eng., B 2009, 163, 184189.

53. Kao, Y.-F.; Chen, T.-J.; Chen, S.-K.; Yeh, J.-W. Microstructure and mechanical property of as-cast, -homogenized, and -deformed AlxCoCrFeNi $(0<=\mathrm{x}<=2)$ high-entropy alloys. J. Alloys Compd. 2009, 488, 57-64.

54. Li, C.; Li, J.C.; Zhao, M.; Jiang, Q. Effect of aluminum contents on microstructure and properties of AlxCoCrFeNi alloys. J. Alloys Compd. 2010, 504 (Supplement 1), S515-S518.

55. ASTM G31 REV A.; ASTM International: West Conshohocken, PA, USA, 2012.

56. ASTM G102-89; ASTM International: West Conshohocken, PA, USA, 2010.

57. Haynes, W.M.; Lide, D.R. CRC Handbook of Chemistry and Physics, 91st ed.; CRC Press: Boca Raton, FL, USA, 2010.

58. Al-Fozan, S.A.; Malik, A.U. Effect of seawater level on corrosion behavior of different alloys. Desalination 2008, 228, 61-67.

59. Ezuber, H.; El-Houd, A.; El-Shawesh, F. A study on the corrosion behavior of aluminum alloys in seawater. Mater. Des. 2008, 29, 801-805.

60. Miller, M.K.; Liaw, P.K. Bulk metallic Glasses: An Overview; Springer: New York, NY, USA, 2008.

61. Natishan, P. Indroduction to Corrosion Resistance of Bulk Materials. ASM Handbook Volume 13A: Corrosion: Fundamentals, Testing, and Protection; ASM International: Novelty, OH, USA, 2003; pp. 687-688.

62. Miracle, D.; Miller, J.; Senkov, O.; Woodward, C.; Uchic, M.; Tiley, J. Exploration and Development of High Entropy Alloys for Structural Applications. Entropy 2014, 16, 494-525. 
63. Gangloff, R.P. Crack size effects on the chemical driving force for aqueous corrosion fatigue. $M T A$ 1985, 16, 953-969.

(C) 2014 by the authors; licensee MDPI, Basel, Switzerland. This article is an open access article distributed under the terms and conditions of the Creative Commons Attribution license (http://creativecommons.org/licenses/by/3.0/). 